\title{
Технологическая оценка сорта винограда Первенец Магарача для коньячного производства
}

Ольга Алексеевна Чурсина, д-р техн. наук, ст. науч. сотр., гл. науч. сотр. лаборатории коньяка, olal45@mail.ru; Людмила Алексеевна Легашева, мл. науч. сотр. лаборатории коньяка, lusi2402@gmail.com;

Виктор Афанасьевич Загоруйко, д-р техн. наук, профессор, гл. науч. сотр. лаборатории коньяка, зав. лабораторией коньяка, vikzag51@gmail.com

Федеральное государственное бюджетное учреждение науки «Всероссийский национальный научно-исследовательский институт виноградарства и виноделия «Магарач» РАН», Россия, Республика Крым, 298600, г. Ялта, ул. Кирова, 31

\begin{abstract}
В статье представлены результаты исследования физико-химических и биохимических показателей винограда, компонентов ароматобразующего комплекса виноматериалов и молодых коньячных дистиллятов, выработанных из сорта винограда Первенец Магарача селекции Института «Магарач», произрастающего в Республике Крым, для его технологической оценки. Показано, что сорт обладает достаточно высоким потенциалом и удовлетворяет всем требованиям для производства качественной продукции. Среди характерных свойств винограда важное технологическое значение имеют низкие показатели способности к отдаче фенольных веществ, массовой концентрации фенольных веществ в сусле и склонности их к окислению. Установлена взаимосвязь между биохимическими показателями винограда и основными группами летучих примесей виноматериала и дистиллята. Выявлены особенности состава основных летучих компонентов коньячных виноматериалов и молодых коньячных дистиллятов, характеризующихся повышенной долей высших спиртов и пониженным содержанием средних эфиров. Проведенные исследования являются этапом научно обоснованного формирования сырьевой базы коньячного производства Российской Федерации.
\end{abstract}

Ключевые слова: виноматериал; коньячный дистиллят; физико-химический показатель; активность монофенолмонооксигеназы; фенольные вещества; средние эфиры; высшие спирты; качество.

$\mathrm{B}$ ведение. Основным направлением государственной политики в сфере АПК явцяется разработка экомогизированных техномогий, направленных на повышение эффективности использования естественных ресурсов при сохранении окружающей среды Аля получения высококачественной, экологически чистой и безопасной продукции. Необходимость сокращения использования пестицидов в виноградарском секторе привлекает внимание к потенциальным возможностям но-

\footnotetext{
Как цитировать эту статью:

Чурсина О.А., Легашева Л.А., Загоруйко В.А. Технологическая оценка сорта винограда Первенец Магарача для коньячного производства // «Магарач». Виноградарство и виноделие, 2019; 21(3); С. 272-276.

DOI 10.35547/IM.2019.21.3.016

How to cite this article:

Chursina O.A., Legasheva L.A. Zagoruyko V.A. Technological assessment of 'Pervenets Magaracha' grapes for brandy assessment of 'Pervenets Magaracha' grapes for brandy production. Magarach. Vinogradarstvo i vinodelie-
Viticulture and Winemaking. 2019; $21(3): 272-276$.

DOI 10.35547/IM.2019.21.3.015 (in Russian)

УДК 663.241:663.253

Поступила 15.08.2019

Принята к публикации 20.08.2019

(САвторы, 2019
}

O R I G I N A L R E S E A R C H

\section{Technological assessment of 'Pervenets Magaracha' grapes for brandy production}

Olga Alekseevna Chursina, Ludmila Alekseevna Legasheva, Victor Afanasievich Zagoruyko

Federal State Budget Scientific Institution All-Russian National Research Institute of Viticulture and Winemaking Magarach of the RAS, 31 Kirova Str., 298600

Yalta, Republic of Crimea, Russian Federation

The article summarizes study findings on physico-chemical and biochemical parameters of grapes, aroma-building complex components of base wines and young brandy distillates produced from 'Pervenets Magaracha' grapes of the Institute Magarach breeding grown in the Republic of Crimea. The study was conducted to assess suitability of the cultivar for brandy production It has been demonstrated that the cultivar possesses sufficiently high potential and meets all the requirements for the production of quality products. Among grape characteristics, low rates of phenolic substances release, mass concentration of phenolic substances in the must and low susceptibility to oxidation are the ones essential for production. The relationship was established between the biochemical parameters of grapes and the principal groups of volatile impurities of the wine material and distillate. Composition peculiarities of the main volatile components of brandy wine materials and young brandy distillates characterized by higher fraction of higher alcohols and low content of medium esters were determined. The conducted studies are a step in the evidence-based formation of brandy production data base in the Russian Federation.

Key words: base wine; brandy distillate; physico-chemical indicator; monophenolmonooxygenase activity; phenolic substances; medium esters; higher alcohols; quality.

вых сортов межвидовой селекции с групповой устойчивостью к биотическим (паразитарные, грибные заболевания, вредители) и абиотическим (засуха, засоленность, морозостойкость) факторам, что определяет их перспективность Аля органического виноградарства и биодинамического виноделия [1-8]. При возАелывании этих сортов обеспечивается чистота окружающей среды, сохранение биоценозов за счет уменьшения применения среАств химической защиты, а также повышение санитарного состояния виноградных насаждений.

Адаптация винограда к неблагоприятным условиям среды Аостигается с помощью различных механизмов: генетических, биохимических, физиологических, структурных и Аругих, опреАеляющих особенности метаболических процессов белкового и углеводного обменов, синтеза различных компонентов (белков, аминокислот, высокомолекулярных углеводов, фенольных соединений, минерацьных веществ, сахарозы и др.), интенсивности окислительных ферментов и т.А., совокупное воздействие которых влияет на формирование специфических свойств сорта [9-12].

В коньячном производстве традиционно используются классические сорта винограда вида Vitis vinifera, в то время как в ряде стран СНГ (Республика Молдова, Украина) получен поможительный опыт применения сортов с групповой устойчивостью Аля получения спиртных напитков [13, 14]. Широкое 
распространение на виноградниках Российской Федерации получим технический сорт винограда Первенец Магарача семекции Института «Магарач» [15]. Сорт выведен среднепозднего срока созревания методом генеративной гибридизации от скрещивания сорта Ркацители и гибридной формы Магарач № 2-57-72 (Мцване кахетинский х Сочинский черный) [16], характеризуется высокой урожайностью (125-145 ц/га) и морозоустойчивостью, слабовосприимчив к мимдью и серой гними. Произрастает в настоящее время преимущественно в Краснодарском крае, площадь посаАки составцяет более 1880 га [17], прослеживается тенденция к Аамьнейшему ее расширению. Свойства винограда и состав полученных из него продуктов зависят от целого ряда эколого-кмиматических, агротехнических и технологических факторов [18-27], вцияние которых на качество коньячных виноматериалов и Аистиццятов изучено недостаточно, что наряду с отсутствием законодатемьной базы и научно обоснованной техномогии производства спиртных напитков сдерживает широкое внеАрение устойчивых сортов в коньячное производство Российской ФеАерации.

Цемью исследований явмялось изучение основных показателей физико-химического и биохимического состава винограда, компонентов ароматобразующего комплекса виноматериалов и молодых коньячных Аистимлятов из сорта винограда Первенец Магарача с цемью его техноцогической оценки.

\section{Объекты и методы исследований}

Материалом исследований явцялся сорт винограАа Первенец Магарача селекции Института «Магарач», урожая 2015-2018 гг., произрастающий в Авух географических зонах Республики Крым: ПреАгорной (с. Вимино Бахчисарайского р-на) и Южнобережной (г. ЯАта); коньячные виноматериалы, полученные в условиях микровиноделия по стандартной технологии; молодые коньячные Аистиццяты, выработанные на стендовой установке методом Авойной сгонки по шарантской технологии. Всего бымо приготовмено 36 партий коньячных виноматериалов и молодых коньячных Аистиццятов. В качестве контромя использовали сорт винограда Ркацители (родитемьская форма Первенца Магарача).

Анализ винограда осуществцяли согласно «Методике оценки сортов винограда по физикохимическим и биохимическим показатемям» (РА 0033483.042-2005). Анализ химического состава виноматериацов проводими общепринятыми методами [28]. Исследование ароматобразующего комплекса виноматериалов и Аистимлятов осуществцяли путем газохроматографического разАеления компонентов на хроматографе Agilent Technology 6890 с массспектрометрическим Аетектором. Органолептическую оценку виноматериалов и Аистиццятов проводили с привлечением Аегустационной комиссии ФГБУН «ВННИИВиВ «Магарач» РАН». В исслеАованиях использоваци микробиологически стойкие виноматериацы, по качеству не ниже удовцетворительной оценки. Результаты проведенных исследований систематизироваци, обрабатываци методами математической статистики, с применением программного обеспечения компьютерных технологий.

\section{Обсуждение результатов}

Проведенный нами анациз винограда показац, что по основным физико-химическим показателям (массовая концентрация сахаров и титруемых кислот) сорт винограда Первенец Магарача полностью соответствует нормативным требованиям. Техническая его зрелость с накоплением массовой концентрации сахаров не менее 160 г/Ам ${ }^{3}$ наступает в Крыму на 2-3 недеми раньше, чем у сорта винограда Ркацители. При сравнительно равном уровне сахаров сорт винограда Первенец Магарача характеризовался более высокими средними значениями массовой концентрации титруемых кислот (на 27 \%), и соответственно более низкой величиной $\mathrm{pH}$ сусла (табц.), что соответствует рекомендациям по оптимацьному составу коньячных виноматериалов [25, 29].

Установлены также и Аругие отмичительные признаки сорта винограда Первенец Магарача по ряду физико-химических и биохимических показателей. Сорт характеризовался более высокими значениями показателей активности монофенолмонооксигеназы (на $26 \%$ ), но более низкой способностью к отдаче фенольных веществ при настаивании мезги (в 1,3 раза), а также невысокой массовой концентрацией фенольных веществ в сусле (в 1,7 раза). Эти показате и имеют важное технологическое значение, т.к. высокое содержание полифенолов в сусле и виноматериаце может способствовать снижению качества дистиц ята за счет образования ацетацьдегида при окислении этанола в процессе перегонки вина и уменьшения концентраций ценных

Таблица. Физико-химические и биохимические показатели винограда сортов Первенец Магарача и Ркацители

Table. Physico-chemical and biochemical parameters of grapes of 'Pervenets Magaracha' and 'Rkatsiteli' cultivars

\begin{tabular}{|c|c|c|}
\hline \multirow{2}{*}{ Наименование показателя } & $\begin{array}{l}\text { Первенец } \\
\text { Магарача }\end{array}$ & Ркацители \\
\hline & \multicolumn{2}{|c|}{ Аиапазон/среднее значение } \\
\hline $\begin{array}{l}\text { Массовая концентрация сахаров } \\
\text { сусла, г/АM }\end{array}$ & $\frac{162-218}{193}$ & $\frac{156-236}{193}$ \\
\hline $\begin{array}{l}\text { Массовая концентрация титруемых } \\
\text { кислот, г/Ам }\end{array}$ & $\frac{5,5-9,8}{7,9}$ & $\frac{5,0-6,9}{6,2}$ \\
\hline Вемичина рН сусла (pH), еА. & $\frac{2,9-3,3}{3,1}$ & $\frac{3,0-3,4}{3,2}$ \\
\hline 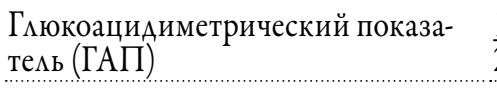 & $\frac{1,9-3,6}{2,5}$ & $\frac{2,5-3,7}{3,1}$ \\
\hline $\begin{array}{l}\text { Показатель технической зрелости } \\
\text { (ПТЗ) }\end{array}$ & $\frac{153-223}{180,3}$ & $\frac{145-273}{196}$ \\
\hline $\begin{array}{l}\text { Массовая концентрация фенольных } \\
\text { веществ в сусле }\left(\Phi B_{\text {исх }}\right), \text { мг/Aм }\end{array}$ & $\frac{179-281}{225}$ & $\frac{236-511}{376}$ \\
\hline $\begin{array}{l}\text { Способность винограда к отааче } \\
\text { фенольных веществ при настаива- } \\
\text { нии мезги }\left(\Phi B_{\text {нм }}\right), \text { мг/Ам }{ }^{3}\end{array}$ & $\frac{162-332}{249}$ & $\frac{145-521}{330}$ \\
\hline $\begin{array}{l}\text { Скмонность сусла к окислению } \\
\left(\Phi B_{\text {ок }}=\Phi B_{\text {исх }}-\Phi B_{\text {ох }} / \Phi B_{\text {исх }}\right), \%\end{array}$ & $\frac{0,5-9,2}{3,5}$ & $\frac{0,5-7,5}{3,3}$ \\
\hline $\begin{array}{l}\text { Технологический запас фенольных } \\
\text { веществ винограда (ТЗФВ), мг/Ам }\end{array}$ & $\frac{521-953}{649}$ & $\frac{452-696}{614}$ \\
\hline $\begin{array}{l}\text { Активность монофеноммоноокси- } \\
\text { геназы (МФМО), у.е./см³ }\end{array}$ & $\frac{0,023-0,142}{0,081}$ & $\frac{0,019-0,110}{0,064}$ \\
\hline
\end{tabular}


высококипящих амьдегидов [25]. В связи с этим массовую концентрацию фенольных соединений в коньячных виноматериацах рекомендовано ограничивать до уровня $250 \mathrm{мг} / \mathrm{Am}^{3}$. Виноматериалы, полученные из сорта винограАа Первенец Магарача, в полной мере отвечали этим требованиям. Кроме того, несмотря на повышенную оксидазную активность сусла, Аоля полимерных форм фенольных веществ в виноматериалах, выработанных из сорта винограда Первенец Магарача, составика не более $5 \%$, в контроле этот показатель превысим 24 \%. Полученные из сорта винограда Первенец Магарача виноматериалы характеризовались более низким содержанием фенольных веществ (менее $250 \mathrm{Mг} /$ Ам$^{3}$ ) в сравнении с контролем и степенью их окисленности, показатель окисляемости $\mathrm{W}$ составим в опытных образцах $1,4 \mathrm{MB}_{\mathrm{A}} \mathrm{M}^{3} / \mathrm{M \Gamma}$, в контроле только $0,5 \mathrm{mB}_{\mathrm{Am}}{ }^{3} / \mathrm{мг}$.

Эти особенности сорта оказали вмияние и на состав метучих компонентов в опытных виноматериа$\Lambda \mathrm{ax}$, который характеризовался более низкой домей метучих кислот, ацьдегидов и среАних эфиров (рис. 1).

Содержание их снизилось на $22 \%, 48$ \% и 43 \% соответственно. Отмечено также уменьшение массовой концентрации компонентов энантового эфира (на $21 \%)$ и возрастание ценного фенимэтикового спирта (в среднем на 9,5\%).

Массовая концентрация высших спиртов в опытных образцах не превышала их уровень в контроле, однако снижение Аругих метучих компонентов, прежАе всего средних эфиров, вызвало увеличение их АОли в сумме Аетучих примесей.

Эти разАичия в химическом составе не оказа$\Lambda$ существенного влияния на органолептическую оценку опытных виноматериалов из сорта винограАа Первенец Магарача, которые характеризовацись тонким ароматом цветочно-фруктового направления, менее интенсивным, чем в контроле, и свежим гармоничным вкусом. Учитывая особенности созревания коньячных Аистицяятов, такой ненавязчивый «нейтрацьный» аромат виноматериалов явцяется предпосылкой Аця получения качественного спиртного напитка [24, 30-32].

Математическая обработка Аанных позволика выявить тесную взаимосвязь физико-химических и биохимических показателей сорта винограда Первенец Магарача с составом кетучих компонентов виноматериалов.

Парные корреляции установлены между содержанием высших спиртов в коньячных виноматериалах и массовой концентрацией фенольных веществ в сусле $(\mathrm{r}=0,572)$, а также показателем способности винограда к отдаче фенольных веществ при настаивании мезги $(\mathrm{r}=0,701)$. Содержание средних эфиров в виноматериале коррелирует с массовой концентрацией сахаров в винограде $(\mathrm{r}=0,667)$, а также с техномогическим запасом фенольных веществ $(\mathrm{r}=0,564)$, поэтому сбор винограда в стадии технической зрелости будет способствовать более высокому накопмению средних эфиров в ароматобразующем комплексе коньячных виноматериалов и повышению их качества.

Состав метучих примесей молодых коньячных Аистилмятов из сорта винограда Первенец Магарача отличался от контроля также, как и виноматериалов: сниженным содержанием средних эфиров и соответственно возросшей Аолей высших спиртов (рис. 2). Аця качественных характеристик коньячных АистилАятов явАяется важным соотношение этих примесей, оптимальное значение которого приближается к единице [23]. По этому показателю опытные образцы в целом уступали контролю (в 2 раза).

По Аанным органолептического анализа молодые коньячные Аистимляты характеризовацись чистым и строгим букетом цветочно-фруктового направцения, близким к контролю, но менее выраженным, что определимо целесообразность его использования Аля производства коньяков с выдержкой до 3-5 ^ет.

\section{Выводы}

Проведена технологическая оценка сорта винограда Первенец Магарача, изучены основные показа-

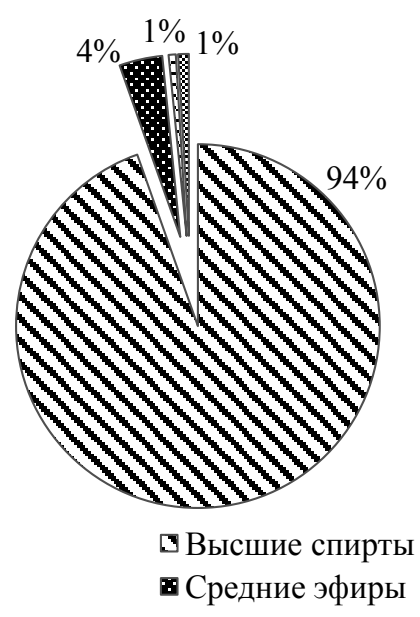

a

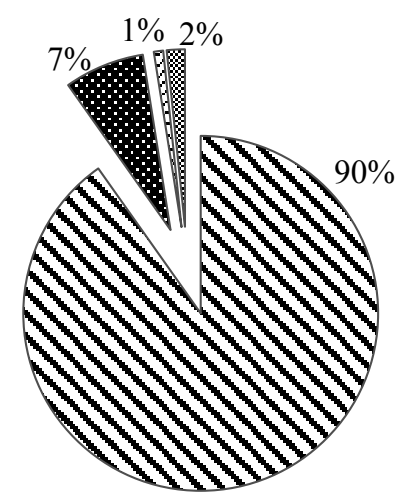

จ Альдегиды 冈 Летучие кислоты 6
Рис. 1. Состав основных групп летучих компонентов коньячных виноматериалов, выработанных из винограда сорта Первенец Магарача (а) и Ркацители (б)

Fig. 1. Composition of the main groups of volatile components of brandy wine materials produced from 'Pervenets Magaracha' (a) and 'Rkatsiteli' (b) grapes
Рис. 2. Состав основных групп летучих компонентов молодых коньячных дистиллятов, полученных из винограда сорта Первенец Магарача (а) и Ркацители (б)

Fig. 2. Composition of the main groups of volatile components of young brandy distillates obtained from 'Pervenets Magaracha' (a) and 'Rkatsiteli' (b) grapes 
тели физико-химического и биохимического состава винограда, компонентов ароматобразующего комплекса виноматериалов и молодых коньячных дистилмятов. Показано, что сорт обладает достаточно высоким потенциалом и удовцетворяет всем требованиям Аля производства качественной продукции. СреАи характерных свойств винограда важное технологическое значение имеют низкие показатели способности к отдаче фенольных веществ, массовой концентрации фенольных веществ в сусле и склонности их к окисмению. Установмена взаимосвязь межАу биохимическими показателями винограда и основными группами метучих примесей виноматериала и Аистимлята. Выявлены особенности состава основных метучих компонентов коньячных виноматериалов и молодых коньячных Аистилмятов, характеризующегося повышенной Аолей высших спиртов и пониженным содержанием средних эфиров. Проведенные исследования явцяются этапом научно обоснованного формирования сырьевой базы коньячного производства Российской Федерации.

\section{Благодарность}

Выражаем благодарность главному виноделу Заралиди Петру ВАадимировичу и администрации OOO «Винное подворье Старого Грека» (г. Анапа, п. Витязево) за оказанную техническую помощь при проведении исслеАований.

\section{Источник финансирования}

Работа выполняется в рамках Государственного задания Минобрнауки России № 0833-2019-0012.

\section{Financing source}

The study was conducted under public assignment № 0833-2019-0012.

\section{Конфликт интересов}

Не заявлен.

\section{Conflict of interests}

Not declared.

\section{Список литературы / References}

1. Михловски М., Раджабов А.К., Хафизова А. Новые перспективные технические гибридные формы селекции винселект Михловски для биологического виноградарства // Известия Тимирязевской сельскохозяйственной академии. 2016. № 5. C. 19-28.

[Mihlovski M., Radzhabov A.K., Hafizova A. [New promising technical hybrid forms of grapevine breeding by vinselekt Michlovsky for biological viticulture]. Izvestiya Timiryazevskoj sel'skohozyajstvennoj akademii, 2016, №5, pp. 19-28 (in Russian)].

2. Шелудько О.Н., Прах А.В., Гугучкина Т.И., Чурсин И.А. Оценка показателей качества сусла из новых сортов винограда греческой селекции, выращенных в Краснодарском крае // Плодоводство и виноградарство Юга России. 2017. № 45 (3). C. 114-121.

[Shelud'ko O.N., Prah A.V., Guguchkina T.I., Chursin I.A. [Quality profile assessment of the grape must obtained from new grapevine cultivars of the Greek breeding grown in the Krasnodar krai]. Plodovodstvo i vinogradarstvo Yuga Rossii, 2017. № 45 (3). pp. 114-121 (in Russian)].

3. Montaigne E., Coelho A., Khefifi L. Economic issues and perspectives on innovation in new resistant grapevine varieties in France. Wine Economics and Policy. 2016. Vol. 5. Issue 2. P. 73-77.
Чурсина O.А., Аегашева А.А.,

Загоруйко B.A.
4. Fuller K.B., Alstonb J.M., Sambucciba O.S. The value of powdery mildew resistance in grapes: Evidence from California. Wine Economics and Policy. 2014. № 3. P. 90-107.

5. Pedneault K., Provost C. Fungus resistant grape varieties as a suitable alternative for organic wine production: Benefits, limits, and challenges. Scientia Horticulturae. 2016. № 208. P. 57-77.

6. Reeve J.R., Carpenter-Boggs L., Reganold J.P., York A.L., McGourty G., McCloskey L.P. Soil and winegrape quality in biodynamically and organically managed vineyards. Am. J. Enol. Vitic. 2005. № 56. P. 367-376.

7. Pavloušek P., Kumšta M. Profiling of primary metabolites in grapes of interspecific grapevine varieties: sugars and organic acids. Czech J. FoodSci. 2011. № 29. P. 361-372. DOI: 10.17221/257/2010-CJFS.

8. Slegers A., Angers P., Ouellet É., Truchon T., Pedneault K. Volatile compounds from grape skin, juice and wine from five interspecific hybrid grape cultivars grown in Quebec (Canada) for wine production. Molecules. 2015. № 20. P. 10980-11016. DOI: $10.3390 /$ molecules200610980.

9. Ненько Н.И., Ильина И.А., Сундырева М.А., Киселева Г.К., Запорожец Н.М., Схаляхо Т.В. Особенности адаптации межвидовых гибридов винограда к низкотемпературному стрессу в контролируемых условиях среды // Садоводство и виноградарство. 2015. № 6. С. 28-34.

[Nen'ko N.I., Il'ina I.A., Sundyreva M.A., Kiseleva G.K., Zaporozhec N.M., Skhalyaho T.V. [Adaptation peculiarities of interspecific grapevine hybrids to low-temperature stress in a controlled environment]. Sadovodstvo i vinogradarstvo, 2015. № 6. pp. 28-34 (in Russian)].

10. Сундырева М.А., Ушакова Я.В., Антоненко М.В. Метаболические изменения у сортов винограда с различной устойчивостью при заражении милдью // Хранение и переработка сельхозсырья. 2017. № 12. С. 15-23.

[Sundyreva M.A., Ushakova YA.V., Antonenko M.V. [Metabolic changes in grapevine cultivars with various resistance to mildew infection]. Hranenie $i$ pererabotka sel'hozsyr'ya. 2017. № 12. P. 15-23 (in Russian)].

11. Погосян К.С. Физиологические особенности морозоустойчивости виноградного растения. Ереван: Изд-во АН Армянской ССР, 1975. - 237 с.

[PogosyanK.S.Fiziologicheskieosobennostimorozoustojchivosti vinogradnogo rasteniya [Physiological peculiarities of frost resistance of a grape plant]. Erevan, AN Armyanskoj SSR Publ., 1975. 237 p. (in Russian)].

12. Landrault N., Poucheret P., Ravel P., Gasc F., Cros G., Teissedre P.L. Antioxidant capacities and phenolics levels of French wines from different varieties and vintages. J. Agric. Food Chem. 2001. № 49 (7). P. 3341-3348. DOI: 10.1021/ jf010128f.

13. Таран А. КВИНТ - новый лидер в Молдавском виноделии // wine-and-spirits.md: ежедн. интернет-изд. 2016. 13 окт. URL: https://wine-and-spirits.md/kvint-novyj-lider-vmoldavskom-vinodelii/ (дата обращения: 01.08.2019).

[Taran A. KVINT - novyjlider v moldavskom vinodelii [KVINT a new leader in Moldova winemaking] // wine-and-spirits.md: ezhedn. internet-izd. 2016. 13 okt. URL: https://wine-andspirits.md/kvint-novyj-lider-v-moldavskom-vinodelii/ (acess date: 01.08.2019)].

14. Анализ структуры ОАО «Агропромышленная фирма «Таврия» и ассортимента выпускаемой продукции. URL: https://ekonom-buh.ru/materialy-diplomnykh-i-kursovykh /550-analiz-struktury-oao-agropromyshlennaya-firmatavriya-i-assortimenta-vypuskaemoj-produktsii.html (дата обращения: 01.08.2019). 
[Analiz struktury OAO "Agropromyshlennaya firma "Tavriya" $i$ assortimenta vypuskaemoj produkcii [Structure analysis of Agro-industrial firm Tavria and the assortment of its produce]. URL: https://ekonom-buh.ru/materialy-diplomnykh-ikursovykh/550-analiz-struktury-oao-agropromyshlennayafirma-tavriya-i-assortimenta-vypuskaemoj-produktsii.html (acess date: 01.08.2019)].

15. Агеева Н.М., Аванесьянц Р.В. Биохимические особенности производства коньячных виноматериалов. Краснодар, 2011. 135 c

[Ageeva N.M., Avanes'janc R.V. [Biochemical peculiarities of brandy wine material production]. Krasnodar, 2011, 135 p. (in Russian)].

16. Авидзба А.М., Иванченко В.И., Волынкин В.А., Олейников Н.П., Клименко В.П., Полулях А.А., Рошка Н.А. Селекционные сорта винограда НИВиВ «Магарач» - национальное достояние Украины. Ялта: НИВиВ «Магарач», 2008. - 32 c.

[Avidzba A.M., Ivanchenko V.I., Volynkin V.A., Oleynikov N. P., Klimenko V. P., Polulyakh A. A., Roshka, N. A. Selective grapevine varieties of NIViV Magarach - a national treasure of Ukraine] Yalta: NIViV Magarach, 2008. 32 p. (in Russian)].

17. Хиабахов Т.С. Сырьевая база коньячного производства // Виноделие и виноградарство. 2002. № 2. С. 12-14.

[Hiabahov T.S. Syr'evaya baza kon'yachnogo proizvodstva [Raw materials base for brandy production]. Vinodelie $i$ vinogradarstvo. 2002. № 2. pp. 12-14 (in Russian)].

18. Радчевский П.П., Ачкасова Е.В. Особенности проявления регенерационной способности у черенков технических сортов винограда селекции Института винограда и вина «Магарач» - Первенец Магарача, Подарок Магарача и Цитронный Магарача // Научный журнал КубГАУ. 2015. № 114 (10). C. 1208-1229.

[Radchevskij P.P., Achkasova E.V. [Regenerative capacity peculiarities of the cuttings of wine grapevine cultivars (breeding of the Institute of Grape and Wine) Magarach 'Pervenets Magaracha', 'Podarok Magaracha' and 'Cytrony Magaracha']. Nauchnyj zhurnal KubGAU [Scientific journal of Agrarian Kuban State University]. 2015. № 114 (10). pp. 1208-1229 (in Russian)].

19. Оселедцева И.В., Кирпичева Л.С. Оценка степени влияния сортового фактора на варьирование параметров состава легколетучей фракции коньячных виноматериалов и молодых коньячных дистиллятов // Вестник АПК Ставрополья. 2015. № 1 (17). С. 246-252.

[Oseledceva I.V., Kirpicheva L.S. [Impact assessment of the varietal factor on variation of parameter composition of the volatile fraction of brandy wine materials and young brandy distillates]. Vestnik APK Stavropol'ya [Agricultural Bulletin of Stavropol Region]. 2015. № 1 (17). pp. 246-252 (in Russian)].

20. Хиабахов Т.С. Основы технологии коньячного производства России. - Новочеркасск, 2001. 159 с.

[Hiabahov T.S. Osnovy tekhnologii kon'yachnogo proizvodstva Rossii [Basics of brandy production technology in Russia]. Novocherkassk, 2001. 159 p. (in Russian)].

21. Скурихин И.М. Химия коньяка и бренди. М.: ДеЛипринт, 2005. 296 с.

[Skurihin I.M. Chemistry of cognac and brandy. Moscow: DeLiprint Publ., 2005. 296 p. (in Russian)].

22. Чурсина О.А., Загоруйко В.А., Легашева Л.А., Мартыновская А.В. Биохимическая оценка винограда для коньячного производства // Проблемы развития АПК региона. 2018. № 1 (33). С. 154-163.

[Chursina O.A., Zagorujko V.A., Legasheva L.A.,
Martynovskaja A.V. [Biochemical assessment of grapes for brandy production.] Problemy razvitija APK regiona. 2018. №1 (33). pp. 154-163 (in Russian)].

23. Чурсина О.А., Легашева Л.А., Загоруйко В.А., Яланецкий А.Я., Соловьева Л.М., Соловьев А.Е., Удод Е.Л., Мартыновская А.В., Гаске З.И., Ульянцев С.О. Влияние сортовых особенностей винограда на качество коньячных виноматериалов // Виноградарство и виноделие: Сб. науч. тр. ФГБУН «ВННИИВиВ «Магарач» РАН». Ялта. 2018. Т. 47. C. $71-74$.

[Chursina O.A., Legasheva L.A., Zagorujko V.A., Yalanetskii A.Ya., Solovyova L.M., Soloviev A.E., Udod E.L., Martynovskaya A.V., Gaske Z.I., Uluantsev S.O. [The impact of varietal peculiarities on the quality of brandy wine materials]. Vinogradarstvo i vinodelie: Sb. Nauchnyh trudov FGBUN VNNIIViV "Magarach" RAN". Jalta, 2018. Vol. 47. pp. 71-74 (in Russian)].

24. Оселедцева И.В., Кирпичева Л.С., Гугучкина Т.И. Химический состав коньячных дистиллятов из сорта Первенец Магарача, выращенного в разных зонах экологического оптимума Краснодарского края // Научные труды ГНУ СКЗНИИСиВ. 2013. Том 4. С. 230-236.

[Oseledceva I.V., Kirpicheva L.S., Guguchkina T.I. [Chemical composition of brandy distillates from 'Pervenets Magaracha' grapes grown in various areas of the ecological optimum of the Krasnodar krai]. Nauchnye trudy GNU SKZNIISiV. 2013. Vol.4. pp. 230-236 (in Russian)].

25. Мартыненко Э.Я. Виноград для производства высококачественных коньяков // Виноград и вино России. 2000. № 2. C. 22-23.

[Martynenko E.Ya. Vinograd dlya proizvodstva vysokokachestvennyh kon'yakov [Grapes for high-quality brandies production]. Vinograd i vino Rossii [Grapes and wine of Russia]. 2000. № 2. pp. 22-23 (in Russian)].

26. Tsakiris A., Kallithrakab S., Kourkoutas Y. Grape brandy production, composition and sensory evaluation. I. Sci. Food Agric. 2014. № 94. P. 404-414. DOI 10.1002/jsfa.6377.

27. Pedneault K., Dorais M., Angers P. Flavor of cold-hardy grapes: Impact of berry maturity and environmental conditions. J. Agric. Food Chem. 2013. № 61. P. 10418-10438. DOI: 10.1021/jf402473u

28. Методы технохимического контроля в виноделии / Под ред. В.Г. Гержиковой. Симферополь: Таврида, 2009. 303 с.

[Gerzhikova V.G. [Techno-chemical control methods in winemaking] Simferopol, Tavrida Publ., 2009. 303 p. (in Russian)].

29. Dhiman A.K., Attri S. Production of Brandy. Handbook of Enology: Principles, Practices and Recent Innovations. / Prof. VK Joshi, editor. - New Delhi: Asiatech Publisher, INC, 2010. $60 \mathrm{pp}$.

30. Guymon J.F. Chemical aspects of distilling wines into brandy. Advances in Chemistry. 1974. Vol. 137. Chapter 11. P. 232-253. DOI: 10.1021/ba-1974-0137.ch011.

31. Lurton L., Ferrari G., Snakkers G. Cognac: production and aromatic characteristics // In: Pigott JH, editor. Alcoholic beverages: sensory evaluation and consumer research. Cambridge: Woodhead Publishing Ltd. 2011. P. 242-266. DOI: 10.1016/B978-0-85709-051-5.50011-0.

32. Ebeler S.E. Analytical chemistry: Unlocking the secrets of wine flavor. Food Rev. Int, 2001. № 17. P. 45-64. DOI: 10.1081/FRI-100000517.

ORCID ID

Чурсина O.A. https://orcid.org/0000-0003-4976-0871 Легашева Л.А. https://orcid.org/0000-0002-5617-1357 